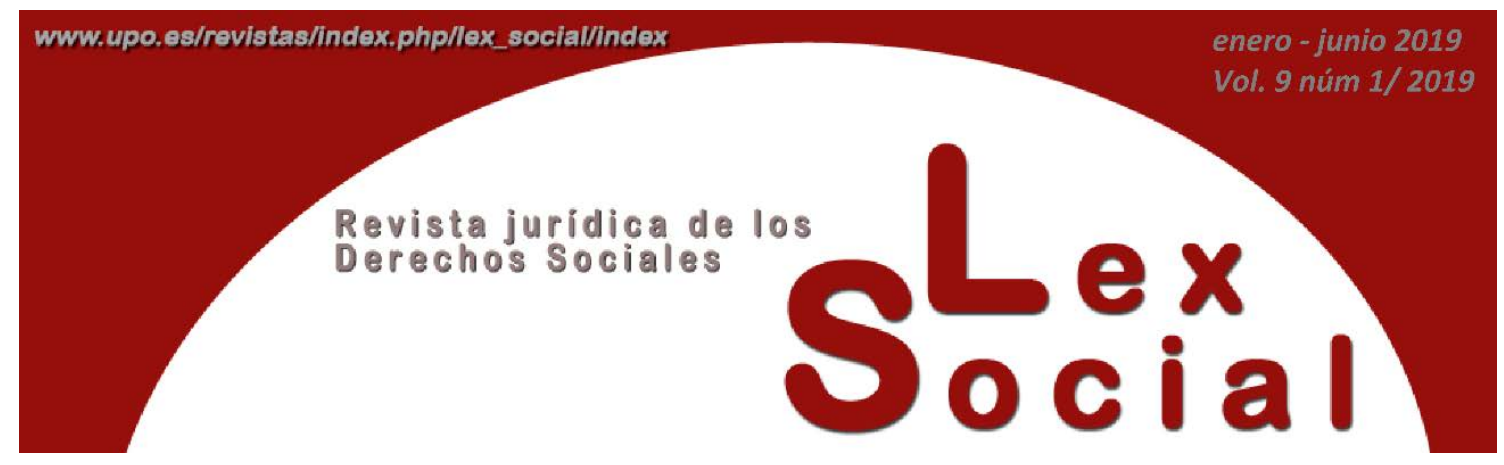

\title{
LA SUSTITUCIÓN DE LOS TRABAJADORES HUELGUISTAS POR MEDIOS TECNOLÓGICOS
}

\author{
THE REPLACEMENT OF STRIKING WORKERS BY \\ TECHNOLOGICAL MEANS
}

\author{
VANESSA CORDERO GORDILLO \\ Profesora Contratada Doctora \\ Departamento de Derecho del Trabajo y de la Seguridad Social \\ Universitat de València ${ }^{1}$
}

Artículo recibido el 30 de enero de 2019

Artículo aceptado el 12 de febrero de 2019

\section{RESUMEN}

Las tecnologías de la información y la comunicación están teniendo una incidencia decisiva en las relaciones de trabajo tanto en el plano individual como en el plano colectivo. Atendiendo a esta última perspectiva, uno de los ámbitos en los que el impacto de los avances tecnológicos se está manifestando con especial intensidad es en el derecho de huelga. En concreto, uno de los principales retos que se plantean es el relativo a la sustitución de los trabajadores huelguistas mediante medios técnicos, lo cual se ha denominado esquirolaje tecnológico. Con estas premisas, el presente trabajo aborda la problemática subyacente a este tipo de prácticas, partiendo de la obsolescencia de la regulación del derecho de huelga en nuestro ordenamiento jurídico y su necesaria adaptación a las nuevas realidades sociales, así como de las resoluciones judiciales que hasta el momento se han pronunciado

\footnotetext{
1 El presente trabajo ha sido realizado en el marco del Proyecto de investigación "Los derechos fundamentales ante el cambio del trabajo subordinado en la era digital” (DER2017-83488-C4-3-R) financiado por el Ministerio de Ciencia, Innovación y Universidades.
} 
sobre esta cuestión. Todo ello con la finalidad de formular propuestas que puedan contribuir a dar solución a los dilemas interpretativos que surgen en estos supuestos.

Palabras clave: Huelga, esquirolaje, tecnologías de la información y la comunicación.

\begin{abstract}
Information and communication technology is having a crucial influence in the labour relationships both in the individual and in the collective field. From this last perspective, one of the fields in which the impact of technological advances is expressing with special intensity is in the right to strike. Specifically, one of the main challenges that they are posing is the substitution of the striking employees by technical means, which has been referred to as technological strikebreaking. With these premises, this work deals with the underlying problems of this type of practices, from the obsolescence of the regulation of the right to strike in our legal system and its adaptation to the new social realities, as well as the judicial decisions that have pronounced on this question so far. The purpose is to make proposals that can contribute to solve the interpretative problems that arise in these cases.
\end{abstract}

KEY WORDS: strike, strikebreaking, information and communication technology.

SUMARIO

1. Introducción

2. La prohibición del esquirolaje en el ordenamiento jurídico español

3. Los vaivenes jurisprudenciales en el abordaje del esquirolaje tecnológico

4. La STC 17/2017

5. Las múltiples dimensiones del esquirolaje tecnológico: posibles respuestas

6. Conclusiones

\title{
1. Introducción
}

Es bien sabido que las tecnologías de la información y la comunicación están teniendo una incidencia decisiva en el ámbito de las relaciones laborales, tanto en el plano individual como en el colectivo. En efecto, la vigilancia y control de la actividad laboral, el empleo del correo electrónico o de las redes sociales en la empresa o el trabajo prestado 
a través de plataformas digitales, son sólo algunos de los desafíos que las tecnologías están planteando al Derecho del Trabajo desde la perspectiva de la relación laboral individual.

$Y$, por lo que respecta a las relaciones colectivas, las innovaciones tecnológicas presentan a la vez un gran potencial para la acción sindical, al proporcionar nuevos cauces de comunicación a los sindicatos, pero también importantes retos tales como el replanteamiento de los mecanismos tradicionales previstos en la legislación, la adaptación de los canales de representación de los trabajadores al contexto tecnológico o su impacto en el ejercicio del derecho de huelga, entre otras materias.

Situándonos, en concreto, en el derecho de huelga, uno de los principales retos que plantean las tecnologías es la utilización de medios técnicos o tecnológicos para la sustitución de trabajadores huelguistas, lo que se ha denominado esquirolaje tecnológico o virtual. Se trata, en definitiva, de una vía a través de la cual el empresario puede conseguir minimizar las repercusiones de la huelga, al posibilitar el mantenimiento de la actividad empresarial con el concurso de pocos o, incluso, de ningún trabajador, mermando o neutralizando así su efectividad.

\section{La prohibición del esquirolaje en el ordenamiento jurídico español}

Es sabido que la regulación del derecho de huelga en nuestro ordenamiento jurídico se encuentra en una norma preconstitucional, el RD-Ley 17/1977, de 4 de marzo, sobre relaciones de trabajo (en adelante RDLRT), que fue declarado acorde con la CE por la STC 11/1981, de 8 de abril, salvo algunos de sus preceptos y sin perjuicio de las matizaciones que dicha sentencia estableció. Esta anómala situación ha determinado que hayan tenido que ser los Tribunales, particularmente, el Tribunal Constitucional, quienes se hayan visto obligados a adaptar dicha regulación a los principios de nuestro sistema constitucional de relaciones laborales ${ }^{2}$ y a dar solución a los múltiples interrogantes y problemas interpretativos que, a lo largo de los más de cuarenta años transcurridos desde la aprobación de la norma, se han planteado.

Un buen ejemplo de ello es la prohibición del esquirolaje prevista en el art. 6.5 RDLRT el cual dispone que mientras dure la huelga, "el empresario no podrá sustituir a los huelguistas por trabajadores que no estuviesen vinculados a la empresa al tiempo de ser comunicada la misma”, prohibición que también se extiende a los supuestos en los que la contratación se realice a través de una ETT (art. 8.a) Ley 14/1994, de 1 de junio, por la que se regulan las empresas de trabajo temporal). Y esta misma modalidad de esquirolaje es la que se tipifica como infracción administrativa muy grave en el art. 8.10 del RD Legislativo 5/2000, de 4 de agosto, por el que se aprueba el texto refundido de la Ley sobre Infracciones y Sanciones en el Orden Social.

\footnotetext{
${ }^{2}$ CRUZ VILLALÓN, J., “25 años de relaciones laborales colectivas. Regulación del derecho de huelga: balance y propuestas normativas”, Relaciones laborales, nº 23-24, 2010 (versión electrónica), p. 4.
} 
En consecuencia, la normativa sólo prohíbe expresamente la contratación ad hoc de trabajadores para sustituir a los huelguistas o la celebración de contratos de puesta a disposición con una ETT con la misma finalidad, lo que se denomina esquirolaje externo. Ante la insuficiencia de esta regulación, por cuanto resulta evidente que la sustitución de trabajadores huelguistas puede efectuarse también por otras vías, el Tribunal Constitucional y el Tribunal Supremo han debido abordar otros supuestos de esquirolaje distintos al contemplado en la norma ${ }^{3}$.

En efecto, pronto se puso de manifiesto que esta sustitución puede llevarse a cabo igualmente recurriendo a otros trabajadores que hayan decidido no ejercer su derecho de huelga, mediante el ejercicio de las facultades de movilidad funcional y/o geográfica o de modificación de las condiciones de trabajo que el ET reconoce al empresario. En este sentido, la STC 123/1992, de 28 de septiembre ${ }^{4}$, se encargó de aclarar que este tipo de sustitución interna o esquirolaje interno tampoco resulta lícito y no puede incardinarse en las medidas de conflicto colectivo a las que se refiere el art. 37.2 CE.

Junto a ello, las transformaciones organizativas, productivas y tecnológicas que han experimentado las empresas en las últimas décadas, con el recurso creciente a la externalización de sus actividades y la expansión de las tecnologías de la información y la comunicación en los procesos productivos, han tenido también un impacto evidente en los instrumentos empleados por los empresarios para reaccionar frente a las huelgas. De este modo, por un lado, la estructuración en red de las empresas determina que muchos empresarios opten por desviar la producción hacia otras empresas cuyos trabajadores no están afectados por la huelga ${ }^{5}$; o que, tratándose la empresa afectada por la huelga de una empresa contratista, la empresa principal opte por contratar a una tercera empresa que realice los trabajos de los trabajadores huelguistas ${ }^{6}$. En estos casos, los Tribunales han diferenciado entre los supuestos en los que entre empresa principal y contratista existe una vinculación especial, como sucede con los grupos de empresa ${ }^{7}$, y aquellos otros en los que no exista un vínculo de esta naturaleza pues, mientras en el primer caso, la

\footnotetext{
${ }^{3}$ PÉREZ REY, J., "El Tribunal Constitucional ante el esquirolaje tecnológico (o que la huelga no impida ver el fútbol). Comentario a la STC 17/2017 (BOE 10 de marzo de 2017)”, Revista de Derecho Social, $n^{\circ}$ 77, 2017, p. 153.

${ }^{4}$ También se consideró vulneradora del derecho de huelga la sustitución de los trabajadores del diario ABC por los jefes de sección, directivos y jefes de área durante la huelga general de 20 de junio de 2002, en la STC 33/2011, de 28 de marzo.

5 SANGUINETI RAYMOND, W., "El derecho de huelga en la encrucijada del cambio tecnológico y productivo”, Trabajo y Derecho, n 14, 2016 (versión electrónica), p. 2.

${ }^{6}$ Este tipo de prácticas han sido denominadas “esquirolaje estructural o comercial”. Vid. GONZÁLEZ ORTEGA, S., "El derecho de huelga: un derecho fundamental acorralado”, Estudios financieros. Revista de Trabajo y Seguridad Social, n ${ }^{\circ}$ 418, 2018, p. 39.

${ }^{7}$ SSTS 11 de febrero de 2015, recurso $n^{\circ}$ 95/2014, sobre el Grupo PRISA; 20 de abril de 2015, recurso $n^{\circ}$ 354/2014, sobre Coca Cola; 3 de octubre de 2018, recurso n ${ }^{\circ} 1147 / 2017$, sobre el Grupo Vocento, y recurso $n^{\circ} 3365 / 2016$, sobre el Grupo Zeta.
} 
conducta de la empresa principal sería vulneradora del derecho de huelga, en el segundo caso no habría ninguna conducta ilícita ${ }^{8}$.

Por otro lado, las tecnologías que permiten sustituir el trabajo humano por máquinas también presentan una gran virtualidad para el mantenimiento de la actividad empresarial durante la huelga, mitigando o neutralizando así sus efectos, una posibilidad que cada vez va a cobrar mayor relevancia habida cuenta de los extraordinarios avances que se están produciendo en el campo de la digitalización y la robótica.

Evidentemente, se trata de situaciones que una norma aprobada en el año 1977 no pudo vislumbrar, por lo que de nuevo ha sido la jurisprudencia la que ha tenido que dar solución a los diversos supuestos que, hasta el momento, se han planteado.

\section{Los vaivenes jurisprudenciales en el abordaje del esquirolaje tecnológico}

Las resoluciones judiciales que han abordado la cuestión de la utilización de medios técnicos para sustituir a los trabajadores huelguistas se refieren al sector de la radiodifusión y televisión, si bien resulta evidente que la tecnificación de los procesos productivos y su eventual aprovechamiento para neutralizar la efectividad de la huelga, puede darse igualmente en otros sectores ${ }^{9}$.

Las primeras sentencias del Tribunal Supremo que se refieren al empleo de medios técnicos durante la huelga llegaron a soluciones contrapuestas, pues mientras en la primera se entiende que la conducta de la empresa vulneró el derecho de huelga, la segunda alcanza la conclusión contraria. En este sentido, cabe citar la STS de 16 de marzo de $1998^{10}$ y la STS de 27 de septiembre de $1999^{11}$, ambas relativas al sector audiovisual ${ }^{12}$.

En la primera de las sentencias referenciadas, en una huelga de los trabajadores de la televisión autonómica andaluza, la empresa había procedido a desviar la señal del satélite desde el centro de producción de Málaga a una unidad móvil situada en Carmona (Sevilla) para emitir desde ésta la programación de Canal Sur Satélite e, igualmente, instaló otra unidad móvil en el Centro de Retevisión de Valencina de la Concepción (Sevilla) para poder emitir los partidos correspondientes a la Eurocopa de Fútbol señalados para los días

\footnotetext{
8 STS 16 de noviembre de 2016, recurso ${ }^{\circ}$ 59/2016. Si bien, la STC 75/2010, 19 de octubre (y las numerosas sentencias que aplicaron idéntica doctrina), consideró que la resolución anticipada de la contrata por parte de la empresa principal como consecuencia de una huelga, lo que provocó la extinción de los contratos de trabajo de los trabajadores de la contratista, vulneraba el derecho de huelga.

9 TALENS VISCONTI, E., “Esquirolaje tecnológico: interrogantes abiertos”, Revista doctrinal Aranzadi social, $\mathrm{n}^{\circ}$ 5, 2013 (versión electrónica), p. 3, quien menciona la posibilidad de programar una cadena de montaje para poder continuar con la producción o la posibilidad de que un convoy de tren o metro pueda circular de manera automática.

${ }^{10}$ Recurso no ${ }^{\circ} 1884 / 1997$.

${ }^{11}$ Recurso no $1825 / 1998$.

${ }^{12}$ Un análisis de las sentencias citadas puede encontrarse en TORRENTE GARÍ, S., "El derecho de huelga y las innovaciones tecnológicas”, Civitas. Revista española de derecho del trabajo, n 102, 2000, pp. 447 y ss.
} 
de huelga, aunque no consta que esta última fuera utilizada. En este supuesto el Tribunal Supremo estima que ha existido una vulneración del derecho de huelga centrando su argumentación en que la programación emitida había excedido de los servicios mínimos, señalando que el derecho de huelga quedaría vacío de contenido si, durante la misma, "se pudieran emitir y mantener, no solo informativos, sino también el resto de la programación habitual”. En consecuencia, esta resolución no abordó la utilización de las tecnologías desde la perspectiva de la sustitución de los trabajadores huelguistas y, por ende, de la prohibición de esquirolaje.

Por su parte, la segunda de las sentencias mencionada, se refiere también a una televisión autonómica, en este caso TV3. Ante la huelga convocada por los trabajadores de dicha empresa, coincidente con un partido de fútbol de la Copa del Rey entre el FC Barcelona y el Atlético de Madrid, que debía retransmitirse con las cámaras y medios técnicos de TV3, el resto de televisiones autonómicas, a través de la FORTA, acuerdan contratar a una tercera empresa para efectuar la retransmisión. Con carácter previo al día de la huelga, TV3 realizó la preprogramación automática de los programas a emitir durante la huelga consistentes en un episodio de una serie de televisión y el partido de fútbol en cuestión. Puesto que la señal llegaba automáticamente a los estadios de TV3, a través del enlace permanente con la Torre de Collserola que hace que reciba interrumpidamente todas las señales que viajan a través de la misma, el partido pudo ser emitido sin intervención de personal alguno, al estar preprogramada la emisión, sin comentarios ni anuncios.

Tras descartar la ilicitud de la actuación del resto de televisiones autonómicas, contratando a una tercera empresa para la retransmisión del partido, la Sala pasa a examinar la conducta de la propia empresa afectada por la huelga, que había utilizado las imágenes captadas por la anterior, y a valorar si ello implicó la utilización de otros trabajadores para la sustitución de los huelguistas. La conclusión, como se ha anticipado, es que no existió vulneración del derecho de huelga afirmando que la empresa no desarrolló su actividad de captación de imágenes, soportando así los efectos de la huelga, siendo ajena al contrato con la empresa que se ocupó de ello, mientras que la retransmisión en las condiciones aludidas fue posible gracias a los avances técnicos y los enlaces preexistentes a la huelga, sin que hubiera sustituido a sus trabajadores en las tareas de captación ${ }^{13}$.

Nuevamente tuvo ocasión de pronunciarse el Tribunal Supremo sobre el empleo de medios técnicos y su incidencia sobre el derecho de huelga en su STS de 4 de julio de $2000^{14}$, en este supuesto con ocasión de una huelga convocada en una cadena de radio, en la cual se emitió programación musical, previamente grabada, de manera automatizada, sin intervención de persona alguna, durante los paros. Sin mucho esfuerzo

\footnotetext{
${ }^{13}$ Si bien, como afirma TORRENTE GARÍ, S., “El derecho de huelga...”, op. cit. p. 458, el hecho de que "no exista "sustitución física” no impide que se alcancen los mismos resultados que si así se hubiera hecho".

${ }^{14}$ Recurso $n^{\circ} 75 / 2000$.
} 
$\operatorname{argumentativo~}^{15}$, la sentencia concluye que no existe ningún precepto en nuestro ordenamiento jurídico que prohíba al empresario utilizar los medios técnicos de los que habitualmente dispone para atenuar las consecuencias de la huelga, de tal manera que, si los huelguistas no han sido sustituidos por otros trabajadores, ni externos ni propios, el derecho fundamental no se ha vulnerado.

Con posterioridad, en términos similares, la STS de 9 de diciembre de $2003^{16}$ estimó lícito que la empresa cubriera el periodo de huelga, aparte de con los programas informativos y la propaganda electoral que se habían fijado como servicios mínimos, con publicidad pregrabada, para cuya emisión únicamente se precisaba pulsar un botón. Además, añade que "la propia característica de la publicidad pone de relieve la ausencia de la actividad propia de una cadena de televisión y compatibiliza el derecho fundamental de huelga con el, también, derecho de continuidad de la actividad empresarial en términos adecuados”.

Aun cuando analizan la cuestión desde una perspectiva distinta, pues se refieren a la emisión como servicios mínimos de una programación previamente grabada, las SSTC 183/2006, 184/2006, 191/2006 y 194/2006, todas de fecha 19 de junio, resultarían decisivas en el posterior cambio de criterio del Tribunal Supremo ${ }^{17}$. En efecto, con ocasión de la huelga general convocada para el 20 de junio de 2002, el RD 531/2002, de 14 de junio, calificó como servicios mínimos, en el ámbito de la radiodifusión sonora y la televisión, "la emisión, dentro de los horarios habituales de difusión, de una programación previamente grabada” y "la producción y emisión de la normal programación informativa”, planteándose la cuestión de si dicha fijación podía considerarse vulneradora del derecho de huelga. Para su enjuiciamiento, el Tribunal Constitucional parte de su doctrina sobre el ejercicio del derecho de huelga y las limitaciones que pueden imponerse al mismo para asegurar el mantenimiento de los servicios esenciales de la comunidad y, aplicándola al supuesto debatido, asevera que, por lo que respecta a la emisión de programación previamente grabada, cabe entender que su consideración como servicio mínimo restringe de manera desproporcionada el derecho de huelga, de un lado, porque aun cuando la citada programación tenga un carácter informativo y pueda afectar al derecho a comunicar y recibir información reconocido en el art. 20.1.d) CE, por su propia condición de pregrabada, no reviste de la actualidad e inmediatez que justificarían la restricción del derecho fundamental. Asimismo, resulta evidente que no toda la programación de la televisión está relacionada con el derecho a la información pues una buena parte de la misma puede ser calificada de "puro entretenimiento”, de modo que no estaría vinculada a la satisfacción de ningún derecho fundamental, libertad pública o bien constitucionalmente reconocido que legitimara la limitación del derecho de huelga.

\footnotetext{
15 TALENS VISCONTI, E., “Esquirolaje tecnológico...”, op. cit. p. 3.

${ }^{16}$ Recurso $n^{\circ} 41 / 2003$.

17 TALENS VISCONTI, E., “Esquirolaje tecnológico...”, op. cit. pp. 4-5.
} 
En definitiva, señala el Tribunal Constitucional que, de esta manera, lo que se persigue es "la no interrupción del servicio de la radiodifusión sonora y de la televisión, con lo que se priva de repercusión apreciable a la huelga, sustrayéndole su virtualidad de medio de presión y de inequívoca exteriorización de los efectos del paro laboral efectivamente producido mediante la exigencia de una apariencia de normalidad del servicio contraria, como ya hemos señalado, al derecho de huelga”.

Tras estos pronunciamientos del Tribunal Constitucional, la siguiente sentencia del Tribunal Supremo que abordó el esquirolaje tecnológico fue la STS de 11 de junio de $2012^{18}$ la cual, pese a declarar la licitud de la conducta empresarial, puso de manifiesto las discrepancias existentes entre los magistrados de la Sala sobre este asunto, presagiando el viraje en su doctrina tan sólo unos meses más tarde. En este caso, de nuevo en una huelga en una televisión autonómica, Euskal Telebista, la Sala tuvo que dilucidar, entre otras cuestiones, si la emisión de publicidad ordinaria y de la Teletienda durante la jornada de huelga, de manera automática y sin intervención humana alguna, constituía una actuación contraria al derecho de huelga. Y llega a la misma conclusión que en sus sentencias anteriores, negando que los pronunciamientos reseñados del Tribunal Constitucional tengan virtualidad para un cambio de criterio, pues en estos últimos lo que se analizaba era la consideración como servicio mínimo de la emisión de programación previamente grabada, y en el caso objeto de enjuiciamiento dicha programación no ha sido considerada servicio mínimo sino que simplemente se ha procedido a su emisión. De esta manera, la sentencia señala que "la actividad podrá realizarse, como cualquier otra, siempre que no se asignen a ella trabajadores encargados de los servicios mínimos, es decir, si se realiza con personal no huelguista y sin utilizar personal incluido en la prohibición de sustitución del art. 6.5 del Real Decreto-Ley 17/1977, o si se realiza de forma totalmente automática”, como acontecía en este caso.

Con todo, esta sentencia cuenta con un voto particular $^{19}$ en el que el magistrado discrepante sostiene que no se ha efectuado una adecuada ponderación entre el derecho de fundamental a la huelga, que debe considerarse prevalente, y la libertad de empresa. Partiendo de esta premisa afirma que si se admite la emisión de programas pregrabados, teniendo en cuenta que la mayor parte de los programas de la parrilla televisiva lo están, ello equivaldría a que la trascendencia social de las huelgas en este tipo de empresas sería casi nula y, en consecuencia, su ejercicio quedaría prácticamente vacío de contenido ${ }^{20}$. A ello añade que la STC 183/2006, pese a referirse a un supuesto distinto, contiene elementos que pueden extrapolarse más allá del caso concreto que resuelve, en particular, que la limitación de la efectividad del derecho debe interpretarse de manera restrictiva, haciendo prevalecer el criterio de la máxima efectividad del derecho fundamental. Asimismo, de la doctrina del Tribunal Constitucional en materia de esquirolaje interno, extrae que el cuestión del esquirolaje tecnológico debería haber sido resuelta tomando en

\footnotetext{
${ }^{18}$ Recurso no $110 / 2011$.

${ }^{19}$ Formulado por el Excmo. Sr. D. Manuel Ramón Alarcón Caracuel.

${ }^{20}$ Por lo demás, cabe destacar que el voto particular utiliza ya la expresión de "esquirolaje tecnológico".
} 
consideración que "la legitimidad de una actuación limitadora de un derecho fundamental como es la huelga no puede derivarse de una interpretación sensu contrario de un precepto legal y que tampoco puede amparase en el ejercicio de potestades directivas que, en definitiva, derivan del principio de libertad de empresa, y que están concebidas y protegidas por el ordenamiento jurídico para "un contexto de normalidad" pero no para una situación de conflicto”.

Son precisamente los argumentos esgrimidos por el voto particular los que fundamentaron el cambio de doctrina respecto al esquirolaje tecnológico en la STS de 5 de diciembre de 2012. Así, en un supuesto sustancialmente idéntico al anterior ${ }^{21}$, la Sala formula la siguiente doctrina: "No sólo en el supuesto de que se utilicen medios humanos (trabajadores asignados a la prestación de servicios mínimos) para la realización de actividades que exceden de los servicios decretados como esenciales, se lesiona el derecho de huelga, sino que también se lesiona este derecho cuando una empresa del sector de radiodifusión sonora y televisión emite programación o publicidad por medios automáticos, en el caso de que dicha actividad empresarial, aun cuando sea mediante la utilización de medios mecánicos o tecnológicos, priva materialmente a los trabajadores de su derecho fundamental, vaciando su contenido esencial de manera que no cabe el uso de las prerrogativas empresariales, aún amparadas en la libertad de empresa, para impedir la eficacia del derecho de huelga, y ello por la propia naturaleza de este derecho y también del de libertad de empresa que no incorpora a su contenido facultades de reacción frente al paro".

Pese a ello, paradójicamente, estima al motivo de recurso formulado por la empresa habida cuenta que, en el caso concreto, no se había acreditado la incidencia que dicha actividad empresarial había tenido sobre la huelga, en el sentido de dejarla vacía de contenido, o de desactivar o aminorar la presión asociada a su ejercicio. De ello se desprende que no siempre que se produzcan este tipo de conductas se tratará de una actuación contraria al derecho de huelga sino que será necesario demostrar su impacto en la huelga, vaciándola materialmente de contenido, o neutralizando o mitigando sus efectos $^{22}$.

Como era de esperar, esta sentencia contó con dos votos particulares en los que seis magistrados (los dos que formularon cada voto más dos que se adhirieron a cada uno de ellos) manifestaron su discrepancia con el parecer mayoritario de la Sala, lo que demuestra que el esquirolaje tecnológico es una cuestión que dista de estar resuelta ${ }^{23}$, particularmente si tenemos en cuenta la más reciente STC 17/2017.

\footnotetext{
${ }^{21}$ La huelga también tuvo lugar en ETB y durante la misma la empresa había emitido publicidad y Teletienda.

22 PÉREZ REY, J., "El esquirolaje tecnológico: un importante cambio de rumbo en la doctrina del Tribunal Supremo (STS de 5 de diciembre de 2012)”, Revista de Derecho social, no 61, 2013, p. 173.

23 TALENS VISCONTI, E., “Esquirolaje tecnológico...”, op. cit. p. 8.
} 
De hecho, a esta última sentencia alude la STS de 13 de julio de $2017^{24}$ para negar la existencia de esquirolaje tecnológico en la utilización, por una empresa del sector de las telecomunicaciones y durante una huelga que afectaba a una de sus contratistas, de una aplicación que distribuye las llamadas, mediante un algoritmo, a otras empresas subcontratistas cuando existen retrasos relevantes, siendo ésta la operativa habitual empleada por la compañía.

\section{La STC 17/2017.}

La STC 17/2017 ${ }^{25}$ es, hasta el momento, la única resolución en la que el máximo intérprete de la CE se ha pronunciado específicamente sobre el esquirolaje tecnológico. Como en los supuestos abordados por el Tribunal Supremo, se trata igualmente de una huelga en el sector audiovisual y, nuevamente, en una televisión autonómica, Telemadrid, planteándose la posible vulneración del derecho de huelga por la retransmisión, durante la huelga general de 29 de septiembre de 2010, de un partido de la Champions League.

En concreto, de manera resumida, el día de la huelga la señal del partido llegó desde el estadio a la antena de Telemadrid a través de la FORTA. Puesto que un trabajador que se encontraba en control central no había secundado la huelga y, entre sus funciones, se encontraba la conmutación de señales, la señal pudo ser enviada al locutorio donde el locutor, que tampoco estaba en huelga, llevó a cabo la locución. La señal se devolvió automáticamente a grafismo, en lugar de a continuidad (donde todos los trabajadores estaban en huelga) como es habitual. En grafismo, el coordinador, que tampoco estaba en huelga, se encargó de colocar la "mosca” con el símbolo de Telemadrid. La señal capta la “mosca” y la devuelve a control central automáticamente. Asimismo, durante una jornada habitual, la señal se envía desde continuidad al codificador A, pero el día de la huelga fue enviada desde control central al codificador B, que normalmente se utiliza para casos excepcionales.

En este supuesto, el Tribunal Constitucional tuvo que dilucidar dos cuestiones. De un lado, se plantea si los trabajadores no huelguistas realizaron funciones diferentes de las que les correspondían, sustituyendo a los trabajadores huelguistas, lo que configuraría un caso de esquirolaje interno. Partiendo de la doctrina contenida en las SSTC 123/1992 y 33/2011, entiende que la misma no resulta aplicable al supuesto enjuiciado por cuanto, de

\footnotetext{
${ }^{24}$ Recurso n ${ }^{\circ} 25 / 2017$.

${ }^{25}$ Sobre esta sentencia pueden consultarse, entre otros, los comentarios de PÉREZ REY, J., "El Tribunal Constitucional ante el esquirolaje tecnológico...”, op. cit. pp. 151 y ss; MARTÍNEZ MORENO, C., "El ser o no ser de la huelga, el fútbol y el esquirolaje. A propósito de la STC 17/2017, de 2 de febrero, caso Telemadrid”, Derecho de las relaciones laborales, no 9, 2017, pp. 894 y ss; ESCRIBANO GUTIÉRREZ, J., "Derecho de huelga, ius variandi y esquirolaje tecnológico", Temas laborales, no 139, 2017, pp. 217 y ss; GRAU PINEDA, C., "El impacto de las nuevas tecnologías en el derecho de huelga: a propósito de la sustitución de huelguistas por medios tecnológicos”, Nueva revista española de Derecho del Trabajo, ${ }^{\circ}$ 206, 2018 (versión electrónica); TOSCANI GIMÉNEZ, D., "La prohibición de esquirolaje durante la huelga con especial mención al esquirolaje tecnológico", Trabajo y Derecho, n 30, 2017 (versión electrónica).
} 
los hechos declarados probados por el Juzgado de lo Social y el Tribunal Superior de Justicia de Madrid, se desprende que los trabajadores no huelguistas que posibilitaron la retransmisión del partido no realizaron funciones distintas de las que habitualmente desarrollan. Particularmente señala que el trabajador que se encontraba en control central tenía entre sus funciones la de conmutar señales y el coordinador de grafismo, "aun cuando dada su específica función de coordinador normalmente se encargue de controlar el trabajo de los departamentos que coordina, entre ellos el de grafismo” y supervisaba esta tarea, también tenía entre sus funciones generar la “mosca” de Telemadrid.

No obstante, como acertadamente advirtió el voto particular ${ }^{26}$, cabe poner en duda que los trabajadores aludidos no realizaran funciones diferentes de las que ordinariamente tenían encomendadas. Por lo que respecta al trabajador de control central, entre sus funciones habituales no se encontraba remitir la señal a grafismo sino a continuidad. Pero más llamativo es el caso del coordinador de grafismo pues era coordinador y responsable no sólo del departamento de grafismo sino también de otros departamentos, por lo que se puede entender que ocupaba un puesto de notable responsabilidad, de ahí que sea más dudoso que insertar la "mosca" figurara entre sus funciones. En definitiva, la retransmisión del partido se llevó a cabo con el concurso de un trabajador con un nivel profesional superior al de los trabajadores que secundaron la huelga, lo cual ha sido reputado ilícito en los anteriores pronunciamientos del Tribunal Constitucional en materia de esquirolaje interno.

Excluida la existencia de esquirolaje interno, la sentencia pasa a abordar si la utilización de los medios técnicos de los que dispone la empresa, pero que no son los que emplea habitualmente para retransmitir los partidos, supone una vulneración del derecho de huelga. La respuesta también es negativa aduciendo que no existe precepto alguno en nuestro ordenamiento jurídico que impida al empresario emplear dichos medios técnicos para mantener su actividad durante la huelga. De hecho, afirma que, de prohibirse esta conducta, ello supondría imponer al empresario una conducta de colaboración con la huelga no prevista legalmente. Por lo tanto, "la utilización de los medios ya existentes en la empresa es compatible con el derecho de huelga y no puede extenderse, por vía analógica, a este supuesto la prohibición prevista en el art. 6.5 del Real Decreto-ley 17/197, que se refiere al empleo de los recursos humanos en la empresa, pero no la utilización de sus recurso materiales y tecnológicos”.

Nuevamente, el razonamiento que emplea la sentencia es susceptible de crítica fundamentalmente porque no otorga relevancia al hecho de que el proceso técnico seguido para retransmitir el partido durante la jornada de huelga no era el que habitualmente se ponía en práctica en este tipo de eventos. Es cierto que la empresa no adquirió los medios técnicos con ocasión de la huelga, sino que disponía de los mismos

\footnotetext{
${ }^{26}$ Formulado por el Magistrado Don Fernando Valdés Dal-Ré y al que se adhieren la Magistrada Doña Adela Asua Batarrita y el Magistrado Don Juan Antonio Xiol Ríos.
} 
con anterioridad, pero no es menos cierto que algunos de ellos únicamente eran usados para casos excepcionales (así ocurriría con el codificador B al que se envió la señal).

Igualmente, la argumentación relativa a que el art. 6.5 RDLRT sólo se refiere al empleo de los recursos humanos en la empresa y no a la utilización de sus recursos materiales y tecnológicos carece de solidez, habida cuenta que la norma en cuestión data del año 1977 y resulta evidente que, en ese momento, no pudieron tenerse en cuenta los extraordinarios avances que iban a producirse en el ámbito de las tecnologías de la información y la comunicación y su eventual impacto en la efectividad de la huelga. De este modo, como señala PÉREZ REY ${ }^{27}$, el Tribunal Constitucional se limita a ofrecer argumentos más desde la perspectiva de la legalidad ordinaria que de la interpretación constitucional de los derechos, además de recurrir a una interpretación a contrario sensu, que en resoluciones anteriores había censurado.

A lo anterior cabe añadir que, al afirmar que el derecho de huelga no impone al empresario un deber de colaboración con los huelguistas en el logro de sus propósitos, de tal manera que no tiene por qué abstenerse de utilizar los medios técnicos con los que cuente o de realizar una actividad productiva que pueda comprometer el logro de los objetivos de la huelga, parece configurar una suerte de derecho de defensa de la libertad de empresa frente al derecho de huelga, pudiendo servirse de todos los medios a su alcance para mantener la producción ${ }^{28}$. Una medida que no podría fundamentarse en las medidas de conflicto colectivo a las que se refiere el art. 37.2 CE, dentro de las cuales no se encontraría "la posibilidad de atenuar las consecuencias de la huelga" ${ }^{29}$.

En definitiva, acudiendo de nuevo al voto particular, las enormes posibilidades que los medios técnicos ofrecen a las empresas para limitar o neutralizar la efectividad del derecho de huelga, “requieren respuestas constitucionales también nuevas, que garanticen la protección de los derechos más esenciales de los trabajadores en un grado asimilable al que ofreció nuestra jurisprudencia en el pasado, cuando dichos medios tecnológicos carecían del desarrollo y de la potencialidad restrictiva con los que ahora cuentan”. De lo contrario, como gráficamente expresa PRECIADO DOMÉNECH ${ }^{30}$, "bastará que el día antes de la huelga se "pulse un botón", que asegure la continuidad de la actividad empresarial, o que se empleen medios empresariales tecnológicos ya existentes para desactivar la huelga”.

\section{Las múltiples dimensiones del esquirolaje tecnológico: posibles respuestas}

\footnotetext{
${ }^{27}$ PÉREZ REY, J., “El Tribunal Constitucional ante el esquirolaje tecnológico...”, op. cit. p. 162.

${ }^{28}$ ESCRIBANO GUTIÉRREZ, J., “Derecho de huelga...”, op. cit. p. 226.

${ }^{29}$ PÉREZ REY, J., “El Tribunal Constitucional ante el esquirolaje tecnológico...”, op. cit. p. 162.

${ }^{30}$ PRECIADO DOMÉNECH, C. H., "El esquirolaje tecnológico: un paso más en la sumisión de la persona a la máquina”, Jurisdicción social Blog de la Comisión de lo Social de Juezas y Jueces para la democracia, 23 de febrero de 2017, disponible en http://jpdsocial.blogspot.com/2017/02/el-esquirolaje-tecnologico-unpaso-mas.html [Recuperado: 30 de enero de 2019].
} 
Aun cuando el esquirolaje tecnológico y su incidencia en el derecho de huelga ya ha sido abordado por diversas sentencias, tanto del Tribunal Supremo como del Tribunal Constitucional, no cabe afirmar que se trate, ni mucho menos, de una cuestión resuelta, pues puede manifestarse de maneras muy variadas y en sectores distintos de la radiodifusión y la televisión ${ }^{31}$.

De esta forma, podrían distinguirse los siguientes supuestos:

- Aquellos supuestos en los que el empresario adquiere los medios técnicos o tecnológicos con ocasión de la huelga con la finalidad de neutralizar o, cuanto menos, minimizar sus efectos. A mi juicio, en estos casos quedaría fuera de toda duda la existencia de una conducta vulneradora del derecho de huelga pudiendo aplicarse, por analogía, lo dispuesto en el art. 6.5 RDLRT ${ }^{32}$. De hecho, la propia STC 17/2017 parece entenderlo así de manera implícita ${ }^{33}$.

- Aquellos supuestos, que serán los más frecuentes en la práctica, en los que los medios técnicos o tecnológicos empleados durante la huelga ya existen en la empresa con anterioridad a la misma. A su vez, dentro de ellos, cabría diferenciar, de un lado, entre los casos en los que es necesario el concurso de algún o algunos trabajadores para su puesta en funcionamiento, utilización y/o supervisión y aquellos en los que la máquina funciona de manera totalmente autónoma, sin requerir de ninguna intervención humana; y, de otro lado, entre los casos en que los medios técnicos o tecnológicos son los habituales en el desarrollo de la actividad de la empresa y aquellos en los que no sea así.

Cuando la puesta en funcionamiento, utilización y/o supervisión de la máquina requiera el trabajo de uno o varios trabajadores, lo primero que debería dilucidarse es si estos trabajadores están desarrollando las funciones que habitualmente desempeñan o si, por el contrario, dichas funciones han sido modificadas como consecuencia de la huelga ${ }^{34} \mathrm{y}$, en definitiva, nos encontramos ante un esquirolaje interno. Éste sería el caso del supuesto enjuiciado por la STC 17/2017 pues, aun cuando el Tribunal no lo consideró así, parece que varios trabajadores realizaron funciones que no les correspondían ${ }^{35}$. Por consiguiente, si se llega a la conclusión de que, efectivamente, se ha producido la sustitución de los huelguistas por trabajadores no huelguistas, se habrá vulnerado el derecho de huelga y ello haría innecesario el análisis sobre la existencia de esquirolaje tecnológico ${ }^{36}$.

${ }^{31}$ TASCÓN LÓPEZ, R., El esquirolaje tecnológico, Cizur Menor, Thomson Reuters Aranzadi, 2018, p. 88.

${ }^{32}$ En este sentido, TASCÓN LÓPEZ, R., El esquirolaje tecnológico, op. cit. p. 92; PÉREZ REY, J., "El Tribunal Constitucional ante el esquirolaje tecnológico...”, op. cit. p. 163.

${ }^{33}$ Así, en el último párrafo del FJ $7^{\circ}$ afirma "los medios técnicos ya existían - no fueron adquiridos expresamente para hacer frente a los efectos de la huelga $-\mathrm{y}$ los trabajadores que no secundaron la huelga no realizaron funciones distintas a las que les corresponden".

${ }^{34}$ Lo mismo cabría afirmar si el empresario utilizara sus facultades de movilidad geográfica o de modificación de otras condiciones de trabajo.

${ }^{35}$ De hecho, PÉREZ REY, J., “El Tribunal Constitucional ante el esquirolaje tecnológico...”, op. cit. p. 166, afirma que se trataría más de un supuesto de esquirolaje interno inverso que de un esquirolaje tecnológico.

${ }^{36}$ TASCÓN LÓPEZ, R., El esquirolaje tecnológico, op. cit. p. 101. 
$\mathrm{Si}$, por el contrario, los trabajadores que no secundan la huelga desarrollan sus funciones habituales o la máquina funciona de manera automatizada, sin necesidad de intervención humana alguna, como podría ser el caso de la emisión de programación pregrabada que fue objeto de enjuiciamiento en las SSTS de 11 de junio y 5 de diciembre de $2012^{37}$, debería enjuiciarse si nos encontramos ante un supuesto de esquirolaje tecnológico contrario al derecho de huelga.

En este sentido, cabe entender que, con esta forma de proceder, también se produciría esta vulneración cuando la conducta empresarial vacíe materialmente de contenido el derecho fundamental, como razonó la STS de 5 de diciembre de 2012. No podemos olvidar que la creciente digitalización y automatización de los procesos productivos presenta un enorme potencial para que la empresa pueda continuar su actividad durante la huelga, de tal manera que, pese al amplio seguimiento de la misma, las repercusiones sobre la empresa sean mínimas gracias al uso de las tecnologías ${ }^{38}$. Ello obligaría a atender a las circunstancias de cada caso concreto para valorar si, efectivamente, el empleo de medios técnicos ha conseguido el efecto de neutralizar o, al menos, minimizar la efectividad de la huelga, privando así a los trabajadores de su derecho fundamental ${ }^{39}$.

En todo caso, si la operativa habitual del proceso productivo requiere que la máquina, aun cuando pueda funcionar de manera automática, sea supervisada por trabajadores, fundamentalmente por razones de seguridad, pero esta supervisión se omite durante el periodo de huelga, la conducta empresarial debería considerarse también ilícita ${ }^{40}$. Piénsese, por ejemplo, en el metro sin conductor que ya funciona en algunas ciudades ${ }^{41}$.

Asimismo, resultará clave determinar si los medios técnicos empleados durante la huelga son los que habitualmente se emplean para el desarrollo de la actividad de la empresa o si, en cambio, únicamente se utilizan en circunstancias excepcionales, como sucedía en el supuesto de hecho de la STC 17/2017. Para el caso de que los medios técnicos no sean los habituales, en contra de lo que sostuvo el Tribunal Constitucional en esta sentencia, en mi opinión, debería estimarse vulnerado el derecho de huelga ${ }^{42}$. La argumentación podría ser similar a la que se esgrime en los casos de esquirolaje interno pues, al igual que está prohibido que los trabajadores que no secundan la huelga realicen funciones diferentes de las que tienen ordinariamente encomendadas para sustituir a los trabajadores

\footnotetext{
${ }^{37}$ Aunque, como señala la última de las sentencias citadas, “se supone que algún trabajador al menos tendrá que hacerlos funcionar o controlar y vigilar su funcionamiento".

38 TASCÓN LÓPEZ, R., El esquirolaje tecnológico, op. cit. p. 94.

${ }^{39}$ Defendiendo esta postura al comentar la STC 17/2017, vid. MARTÍNEZ MORENO, C., "El ser o no ser...”, op. cit. p. 901. También TOSCANI GIMÉNEZ, D., “La prohibición de esquirolaje...”, op. cit. p. 5. 40 TODOLÍ SIGNES, A., "El esquirolaje tecnológico como método de defensa ante una huelga”, Actualidad laboral, nº 7, 2014 (versión electrónica), pp. 4-5; TASCÓN LÓPEZ, R., El esquirolaje tecnológico, op. cit. p. 101.

${ }^{41}$ Por ejemplo, en Barcelona algunos trenes funcionan sin conductor, pero existe un centro de control con personal especializado.

${ }^{42}$ En este sentido también PÉREZ REY, J., “El esquirolaje tecnológico...”, op. cit. p. 174.
} 
huelguistas, tampoco pueden emplearse medios técnicos no habituales con la misma finalidad.

En otro orden de consideraciones, el empleo de los recursos tecnológicos de la empresa durante la huelga plantea también problemas específicos en el ámbito del teletrabajo y en el del trabajo prestado a través de plataformas digitales, debido a las dificultades de control de las prácticas de esquirolaje, no sólo tecnológico sino también interno y externo, las cuales se ven facilitadas, precisamente, por las tecnologías. Resulta evidente que conductas de este tipo vulnerarían igualmente el derecho de huelga de los trabajadores huelguistas, pero aquí la problemática fundamental está en que la empresa podría recurrir a otros trabajadores o a otras empresas de cualquier parte del mundo para que sustituyeran a los huelguistas casi con total impunidad, por la dificultad de control y prueba ${ }^{43}$.

\section{Conclusiones}

Cuanto se acaba de exponer pone de manifiesto, una vez más, la inadecuación de la norma preconstitucional para regular un derecho de huelga que debe adaptarse, a golpe de sentencia, a una realidad cada vez más cambiante como consecuencia, aunque no sólo, de la expansión de las tecnologías de la información y la comunicación.

El esquirolaje tecnológico está llamado a adquirir un protagonismo creciente no sólo en el sector de la radio y la televisión, que ha sido el abordado por los pronunciamientos judiciales que, hasta el momento, han analizado esta cuestión, sino también en otros sectores, y puede manifestarse de diferentes maneras ${ }^{44}$. Tal y como se ha razonado, en algunos casos el empleo de las tecnologías durante la huelga constituirá una conducta claramente vulneradora del derecho de huelga, mientras que, en otros, será necesario analizar minuciosamente las circunstancias concurrentes para determinar si nos encontramos ante una violación del derecho fundamental. Ello sin perjuicio de que las tecnologías puedan facilitar igualmente otras modalidades de esquirolaje, señaladamente, el interno.

En consecuencia, a la vista de los extraordinarios avances en robótica e inteligencia artificial que se están produciendo y que continuarán produciéndose en el futuro, cabe pensar que cada vez más actividades humanas van a poder ser sustituidas por las

\footnotetext{
43 GOERLICH PESET, J. Ma " "Ejercicio del derecho de huelga en el contexto de la descentralización productiva” en ASOCIACIÓN ESPAÑOLA DE DERECHO DEL TRABAJO Y DE LA SEGURIDAD SOCIAL, Descentralización productiva: nuevas formas de trabajo y organización empresarial, XXVIII Congreso de la Asociación Española de Derecho del Trabajo y de la Seguridad Social, Madrid, Ediciones Cinca, 2018, p. 181.

${ }^{44}$ Desde una perspectiva comparada, no parece que en los países de nuestro entorno se haya planteado el tema del esquirolaje tecnológico. Con todo, por lo que respecta a Italia y Francia la mayor permisividad con la que se contempla el esquirolaje interno (permitido en ambos países salvo, en el caso de Francia, que el empresario recurra a trabajadores temporales ya existentes para sustituir a los huelguistas), podría llevar a pensar que también el tecnológico se juzgue lícito. Vid. ROTTA, A., "Il crumiraggio tecnologico: una lettura comparata”, Labour \& Law Issues, vol. 4, no. 1, 2018.
} 
tecnologías, total o parcialmente, por lo que, de no establecer unos límites claros a su empleo por parte de la empresa durante una huelga, podemos encontrarnos con que este derecho fundamental quede privado materialmente de contenido, al poderse minimizar, de manera exorbitante, el impacto de la huelga y, consiguientemente, su eficacia como medio de presión de los trabajadores en defensa de sus legítimos intereses.

\section{Bibliografía}

CRUZ VILLALÓN, J., "25 años de relaciones laborales colectivas. Regulación del derecho de huelga: balance y propuestas normativas”, Relaciones laborales, ${ }^{0}$ 23-24, 2010 (versión electrónica)

ESCRIBANO GUTIÉRREZ, J., "Derecho de huelga, ius variandi y esquirolaje tecnológico", Temas laborales, nº 139, 2017

GOERLICH PESET, J. Ma " "Ejercicio del derecho de huelga en el contexto de la descentralización productiva” en ASOCIACIÓN ESPAÑOLA DE DERECHO DEL TRABAJO Y DE LA SEGURIDAD SOCIAL, Descentralización productiva: nuevas formas de trabajo y organización empresarial, XXVIII Congreso de la Asociación Española de Derecho del Trabajo y de la Seguridad Social, Madrid, Ediciones Cinca, 2018

GONZÁLEZ ORTEGA, S., "El derecho de huelga: un derecho fundamental acorralado", Estudios financieros. Revista de Trabajo y Seguridad Social, nº 418, 2018

GRAU PINEDA, C., "El impacto de las nuevas tecnologías en el derecho de huelga: a propósito de la sustitución de huelguistas por medios tecnológicos”, Nueva revista española de Derecho del Trabajo, n 206, 2018 (versión electrónica)

MARTÍNEZ MORENO, C., "El ser o no ser de la huelga, el fútbol y el esquirolaje. A propósito de la STC 17/2017, de 2 de febrero, caso Telemadrid”, Derecho de las relaciones laborales, $\mathrm{n}^{\circ}$ 9, 2017

PÉREZ REY, J., "El esquirolaje tecnológico: un importante cambio de rumbo en la doctrina del Tribunal Supremo (STS de 5 de diciembre de 2012)”, Revista de Derecho social, $\mathrm{n}^{\circ} 61,2013$

- "El Tribunal Constitucional ante el esquirolaje tecnológico (o que la huelga no impida ver el fútbol). Comentario a la STC 17/2017 (BOE 10 de marzo de 2017)”, Revista de Derecho Social, $\mathrm{n}^{\circ}$ 77, 2017

PRECIADO DOMÉNECH, C. H., "El esquirolaje tecnológico: un paso más en la sumisión de la persona a la máquina”, Jurisdicción social Blog de la Comisión de lo Social de Juezas y Jueces para la democracia, 23 de febrero de 2017, disponible en http://jpdsocial.blogspot.com/2017/02/el-esquirolaje-tecnologico-un-paso-mas.html

[Recuperado: 30 de enero de 2019] 
ROTTA, A., “Il crumiraggio tecnologico: una lettura comparata”, Labour \& Law Issues, vol. 4, no. 1, 2018

SANGUINETI RAYMOND, W., "El derecho de huelga en la encrucijada del cambio tecnológico y productivo”, Trabajo y Derecho, n 14, 2016 (versión electrónica)

TALENS VISCONTI, E., “Esquirolaje tecnológico: interrogantes abiertos”, Revista doctrinal Aranzadi social, n 5, 2013 (versión electrónica)

TASCÓN LÓPEZ, R., El esquirolaje tecnológico, Cizur Menor, Thomson Reuters Aranzadi, 2018

TODOLÍ SIGNES, A., "El esquirolaje tecnológico como método de defensa ante una huelga”, Actualidad laboral, nº 7, 2014 (versión electrónica)

TORRENTE GARÍ, S., “El derecho de huelga y las innovaciones tecnológicas”, Civitas. Revista española de derecho del trabajo, $\mathrm{n}^{\circ}$ 102, 2000

TOSCANI GIMÉNEZ, D., "La prohibición de esquirolaje durante la huelga con especial mención al esquirolaje tecnológico”, Trabajo y Derecho, n 30, 2017 (versión electrónica) 